\title{
Standard daily dosage versus pulse dosage of Isotretinoin in acne vulgaris: A hospital based comparative study
}

\section{Aryal E', Shrestha SB ${ }^{2}$, Pokhrel ${ }^{3}$, Bhattarrai $S^{4}$}

'Eliz Aryal, Assistant Professor; ${ }^{2}$ Sanju Babu Shrestha, Assistant Prof; ${ }^{3}$ Govind Pokhrel, Associate Professor; ${ }^{4}$ Sabina Bhattarai, Professor, Kathmandu Medical College, Sinamangal, Kathmandu.

\begin{abstract}
Background: Acne is a multifactorial disease ranging from a couple of comedones and pustules to severe nodulocystic fulminant acne. Isotretinoin(13-cis-retinoic-acid) drug affect all the factors involved in pathogenesis of acne and approved by Food and Drug Administration in 1982. It causes several dose-dependent mucocutaneous and systemic side effects and cost effect

Objective: To assess and compare the efficacy and tolerability of two regimens (daily conventional and pulse dose) in moderate to severe acne vulgaris.

Methodology: This is a prospective randomized comparative study in moderate to severe acne vulgaris in Kathmandu Medical College Teaching Hospital. The patients were randomly divided into two groups (A and B). In group A conventional dose of $20 \mathrm{mg}$ of oral isotretinoin was given daily and in group B $20 \mathrm{mg}$ of oral isotretinoin was given thrice (Pulse Dosage in alternate day) in a week for six months. The baseline haematological, biochemical and radiological (lumbosacral spine) was compare on first, third and six month.

Results: Seventy-four patients were enrolled with mean age of 21.73 years. Patients with daily regimen show good response throughout the therapy for six months $\left(1^{\text {st }}, 3^{\text {rd }} 6^{\text {th }}\right.$ months), where as those in pulse therapy show moderate to poor response during early month and gradually improve by end of sixth month. At end of sixth month, both the regimen show good response and was statistically significant.

Conclusion: However, the pulse dose regimen makes the treatment more acceptable, for patients with acne than the classical standard daily regimen, in term of side effects and cost effectiveness and patient compliance.
\end{abstract}

Key words: Acne; Isotretetoin; Pulse dose; 13-cis-retinoic-acid.

\section{INTRODUCTION}

A cne is a multifactorial disease ranging from a couple of comedones and pustules to severe nodulocystic fulminant acne, affecting 40\% of females between 14-17 years of age and 35\% of males between 16-19 yearsof age $^{1}$. Acneis associated with considerable psychosocial morbidity and affects patients' quality of life with negative impact on emotions, interpersonal relationships, physical activities, social life and professional status ${ }^{2}$. Currently various treatment modalities are used, due to increased resistance of microorganism to common antibiotics, application of oral isotretinion has become

Address for correspondence

Dr. Eliz Aryal

Assistant Professor, Deparment of Dermatology

Kathmandu Medical College Teaching Hospital

E-mail: eliz_aryal@yahoo.com more popular and has proven to be "a wonder drug" over the time effective in allforms of acne grades ${ }^{3}$.

Isotretinion (13-cis-retinoic-acid) is only drug that can affect all the factors involved in pathogenesis of acne. In 1982, Food and Drug Administration (FDA) approved isotretinion for severe cases of nodulocystic acne in dosage of 0.5 to $1 \mathrm{mg} / \mathrm{kg} /$ day for $16-32$ weeks $^{3}$. This regimen is known to produce good results; however, it might cause several dose-dependent mucocutaneous and systemic side effects. Various studies have reinforced different therapeutic regimens (daily, alternate, pulse, low dose) instead of daily conventional dose ${ }^{3}$.

To overcome dosage dependent side effects the present prospective study - A comparative study between conventional dosage proposed by FDA with pulse dose of Isotretinoin in moderate to severe acne vulgaris in 
Nepalase patients, was undertaken. This study with different dosage of isotretinoin was first study done in Nepalese population.

Aims and objective of our study was to assess and compare the efficacy and tolerability (haematological, biochemical) of two regimens (daily conventional, pulse dose) in moderate to severe acne vulgaris.

\section{METHODOLOGY}

This was a prospective randomized comparative study in patients presented with moderate to severe acne vulgaris attending the outpatient clinic in the dermatology department from 2016 to 2017 October in Kathmandu Medical College Teaching Hospital. The study was performed on human subject; thus all patients had given consent and were aware of the study. They were fully informed about the drug and its side-effects. The study was approved by institutional review committee of Kathmandu medical college teaching hospital.

\section{INCLUSION CRITERIA}

- Age above 12 years.

- Participants having moderate to severe facial acne vulgaris

- Participants willing to undergo treatment and follow ups.

\section{EXCLUSION CRITERIA}

- Age less than 12 years

- Pregnant women and women who intend to become pregnant, lactating during the course of treatment

- Participants who intend to consume alcohol during the treatment course.

- Presence of any systemic compromise or any preexisting hyperlipidemia

- Participants not willing for the necessary investigations and regular follow up.

*Married female, pregnant female or desiring to get pregnant or using temporary contraception in reproductive age group were excluded from the ambit of the study. Married females were not included unless primary as well as secondary forms of contraception were adopted and pregnancy tests were negative. Effective contraception was adopted at least one month prior to starting isotretinoin and was continued for one month after its discontinuation. Due to the teratogenic effect of the drug above mentioned precaution were undertaken.
After recording detailed demographic data, the patients were examined under good illumination and patients were finally divided to mild, moderate, severe acne based on severity as described by Pochi ${ }^{4}$.

- Grade 1: Comedones, occasional papules.

- Grade 2: Papules, comedones, few pustules.

- Grade 3: Predominant pustules, nodules, abscesses.

- Grade 4: Mainly cysts, abscesses, widespread scarring.

The patients with moderate to severe acne with grade 3 to grade 4 were randomly divided into two groups ( $A$ and $B$ ); each groups consisted of 37 patients. In group A, conventional dose of $20 \mathrm{mg}$ of oral isotretinoin was given daily and in group B, $20 \mathrm{mg}$ of oral isotretinoin was given thrice (pulse dosage at alternate day) in a week In both groups topical clindamycin $1 \%$ gel was advised twice daily along and white petroleum jelly on lips when required. All patients were advised to visit/follow up at interval of four weeks for twenty -four weeks. The baseline haematological, biochemical and radiological (lumbosacral spine) were evaluated and compared later with same tests done on at the end of first, third and six months of therapy.

Laboratory results were divided into three categories: Normal, Borderline and High. Similarly, side effects were recorded at each visit which included cutaneous, mucosal including eye, neurological and miscellaneous. Psychological evaluation was done in every visit.

The efficacy of the drug was assessed by lesion counts at each visit from baseline according to Global response of inflammatory lesion ${ }^{5}$.

1. Reduction by $80 \%$ : Good

2. Reduction by $50-79 \%$ : Moderate

3. Reduction by $20-49 \%$ : Poor

4. Less than $20 \%$ : No response

Data Analysis: Statistical analysis was performed using the SPSS (Statistical Package for the Social Sciences) software program, version 20 by using univariate and multi variate analysis including the $T$ test and chi- square test.

\section{RESULTS}

A total of 74 patients were enrolled with mean age of 21.73 years (range12-35, median 20.5). The demographic data of the patients in two groups including age, gender, education, family history, religion, ethnicity, duration of acne, acne grade is mentioned in Table 1. 
In our study, we found that patients with daily regimen (group A) show moderate response in $1^{\text {st }}$ and $3^{\text {rd }}$ month, and gradually improvement by end of six month.

\section{Table 1: Demographic Data}

\begin{tabular}{|c|c|c|}
\hline Variables & Frequency & Percentage \\
\hline \multicolumn{3}{|l|}{ Gender } \\
\hline Male & 35 & 47.3 \\
\hline Female & 39 & 52.7 \\
\hline \multicolumn{3}{|l|}{ Religion } \\
\hline Hindu & 48 & 64.9 \\
\hline Muslim & 13 & 17.6 \\
\hline Buddhist & 10 & 13.5 \\
\hline Kirat & 3 & 4.1 \\
\hline \multicolumn{3}{|l|}{ Education } \\
\hline Secondary & 13 & 17.6 \\
\hline Higher Secondary & 22 & 29.7 \\
\hline Bachelor & 32 & 43.2 \\
\hline Master & 7 & 9.5 \\
\hline \multicolumn{3}{|l|}{ Duration of acne } \\
\hline$<6$ month & 8 & 10.8 \\
\hline $6-1$ years & 11 & 14.9 \\
\hline $1-2$ years & 28 & 37.8 \\
\hline$>2$ years & 27 & 36.5 \\
\hline \multicolumn{3}{|l|}{ Acne Grade } \\
\hline Grade 3 & 44 & 59.5 \\
\hline Grade 4 & 30 & 40.5 \\
\hline \multicolumn{3}{|l|}{ Occupation } \\
\hline Student & 34 & 45.9 \\
\hline House wife & 9 & 12.2 \\
\hline Banker & 7 & 9.9 \\
\hline Business & 15 & 25.7 \\
\hline Service & 5 & 6.8 \\
\hline \multicolumn{3}{|l|}{ Ethnicity } \\
\hline Bhramin & 20 & 27.0 \\
\hline Chettri & 15 & 20.3 \\
\hline Newari & 19 & 27.7 \\
\hline Muslim & 13 & 17.6 \\
\hline
\end{tabular}

On other hand, patients with pulse regimen (group B) showed poor response during first month, with gradually improving by third month, and at the end of six month show good response.

When comparing both the regimen we found that patients with daily regimen show good response throughout the therapy for six months $\left(1^{\text {st }}, 3^{\text {rd }}, 6^{\text {th }}\right.$ months), where as those in pulse therapy show moderate to poor response during firstthree months and gradually showed improvement by end of sixth month.

At end of six month, pulse dose showed good response in compare with daily dose, which was statistically significant. Chi Square was done at six month between good and moderate response (Table 2).

In both groups chapped lips and chelitis was more common.

Daily Dose Regimen: During first month(97.2\%) patients presented with chapped lips along with chelitis, followed by xerosis of face (86.4\%),erythematous face $(43.2 \%)$ and photosensitivity was found in $43.2 \%$ along with thinning of hair (32.4\%) and pruritus (40.5\%). (fig :1) With continous couse of therapy cutaneous adverse effects were in decreasing order although chapped lip and chelitis was present throughout six months. (fig.2).

Pulse Dose Regimen: Comparing with daily dose adverse effects were lesser in number, but $81 \%$ had chapped lip, followed by chelitis (72.9) during the first month which gradually improve during course of therapy. (fig:1)

Daily Dose Regimen: In both the groups, mucosal adverse effect was noted. At first month of therapy most of patients presented with red-eye (62.1\%), Epixtasis (54\%), visual disturbance $(51.3 \%)$, followed by dry eye (45.9\%). With continous course of therapy mucosal adverse effects were in decreasing order throughout six months. (Fig. 3)

Table 2: Response of Drug

\begin{tabular}{|c|c|c|c|c|c|c|}
\hline Response & & Good & Moderate & Poor & No response & P value \\
\hline \multirow{2}{*}{$1^{\text {st }}$ Month } & $\mathrm{D}$ & $1(2.7)$ & $27(73.0)$ & $9(24.3)$ & 0 & \multirow{2}{*}{$<0.001$} \\
\hline & $P$ & 0 & 0 & $35(94.6)$ & $2(5.4)$ & \\
\hline \multirow{2}{*}{$3^{\text {rd }}$ Month } & $\mathrm{D}$ & $2(5.4)$ & $32(86.5)$ & $3(8.1)$ & 0 & \multirow{2}{*}{$<0.001$} \\
\hline & $P$ & 0 & $13(35.1)$ & $24(64.9)$ & 0 & \\
\hline \multirow{2}{*}{$6^{\text {th }}$ Month } & $\mathrm{D}$ & $26(70.2)$ & 11(29.7) & 0 & 0 & \multirow{2}{*}{$<0.035$} \\
\hline & $\mathrm{P}$ & 34 (91.8) & $3(8.1)$ & 0 & 0 & \\
\hline
\end{tabular}

Reduction by $80 \%$ : Good, Reduction by $50-79 \%$ : Moderate, Reduction by $20-49 \%$ : Poor, Less than $20 \%$ : No response

D: Daily dose

P: Pulse dose 
Table 3: Summary of previous study of different regimens

\begin{tabular}{|c|c|c|c|c|}
\hline Study & Author & Patients & Duration (weeks) & Result \\
\hline $\begin{array}{l}\text { 1. Intermittent (0-5-0.7mg/kg/day) for } \\
1 \text { week } / \text { month }\end{array}$ & Kayamak et al $^{9}$ & 60 & 24 & Good result \\
\hline $\begin{array}{l}\text { 2. Micronized formulation versus } 1 \mathrm{mg} / \\
\mathrm{kg} / \text { day }\end{array}$ & Strauss et al ${ }^{10}$ & 300 & 29 & $\begin{array}{l}\text { Equivalent to the standard } \\
\text { twice-daily formulation }\end{array}$ \\
\hline 3. Low Dose $20 \mathrm{mg} / \mathrm{kg} / \mathrm{day}$ & Amichai et al ${ }^{11}$ & 638 & 24 & $\begin{array}{l}\text { Good efficacy and lower cost } \\
\text { then higher doses. }\end{array}$ \\
\hline $\begin{array}{l}\text { 4. Low-dose } 20 \mathrm{mg} \text {, alternative plus } \\
\text { clindamycin gel }\end{array}$ & Sardana et al ${ }^{12}$ & 305 & 25 & $\begin{array}{l}\text { Less side effect with equal } \\
\text { efficacy }\end{array}$ \\
\hline
\end{tabular}

Pulse Dose Regimen: In this group mucosal adverse effect was very less comparing with daily regimen. Twenty- seven percentages presented with eye dry at first month and gradually improve by end of six month by sixteen percentages. (fig. 4)

Headache was present in both groups during first month, and gradually improved. Around $24.3 \%$ patients on daily therapy presented with headache followed by depression (10.8\%), insomnia (5.4\%). Similalrly only $18.9 \%$ patients on pulse therapy presented with headache, follow by depression (5.4\%) and insomnia (5.4\%).

Irregular menstrual cycle was present in $24.3 \%$ on patients with daily therapy. Myalgia was seen in (32.4\%) and nausea in (10.8\%) throughout treatment in daily therapy. There were no pregnancies and suicidal tendency reported in both the regimen. Radiograph of the lumbosacral spine were in normal limits in all patients.
Laboratory abnormalities during first month in both groups were insignificant. During third months patients with daily therapy AST (29.7\%), ALT (43.2\%), cholesterol (48.6\%), triglyceride (5.67\%) were in borderline high, at end on six months AST (32.4\%), ALT (29.7\%) were in higher limits. In other hand patients with pulse therapy during $3^{\text {rd }}$ month only AST (10.8\%), ALT (10.8\%), triglyceride (13.5) were in borderline high, and at end of $6^{\text {th }}$ months AST $(8.1 \%)$, ALT $(24.3 \%)$ were in higher limits. None of the patients were discontinued for any laboratory abnormalities. In both the regimen total count (TC), direct count (DC), platelets were in normal limits.

\section{DISCUSSION}

Isotretinoin is a synthetic isomer of all-trans retinoic acid with proven long-term effectiveness in treatment acne. It has been recommended for the treatment of sever nodulocystic acne and in -resistant acne $e^{6,7}$. It is currently the most effective acne treatment available, with reported long-term remission rate up to $70-89 \%{ }^{7}$ and its efficacy, ability to target all the four pathophysiologic factors with high rates of permanent remission and prevention of permanent scarring ${ }^{7}$.

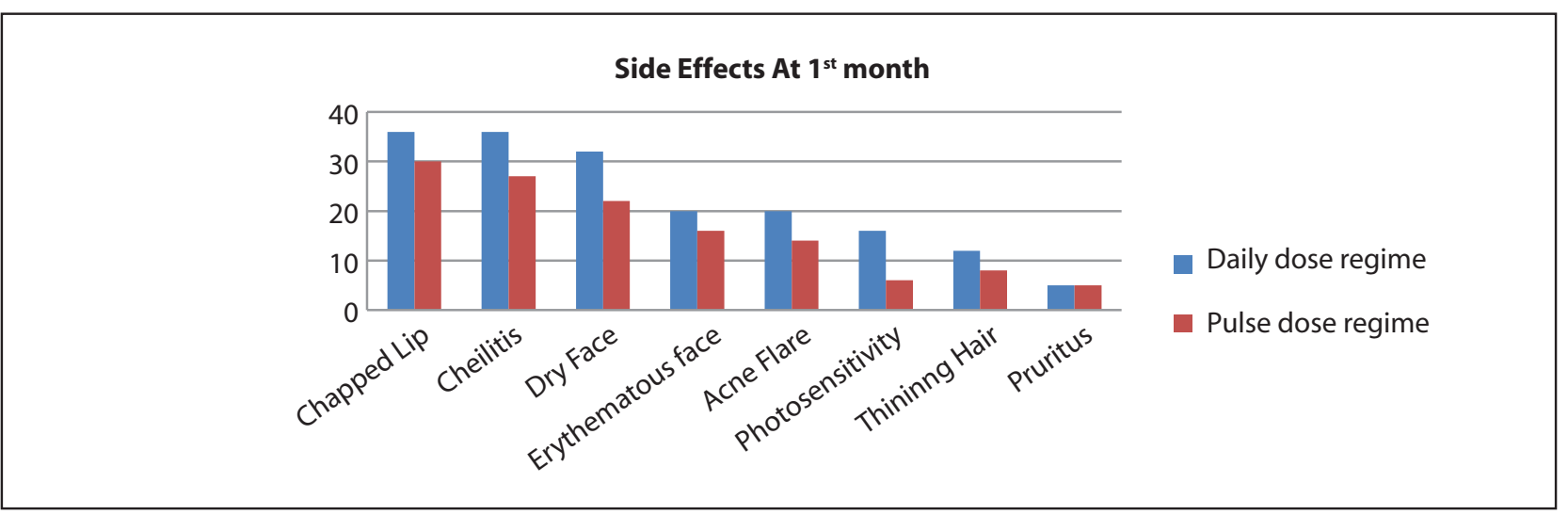

Figure 1: Cutaneous adverse effect at $1^{\text {st }}$ month 


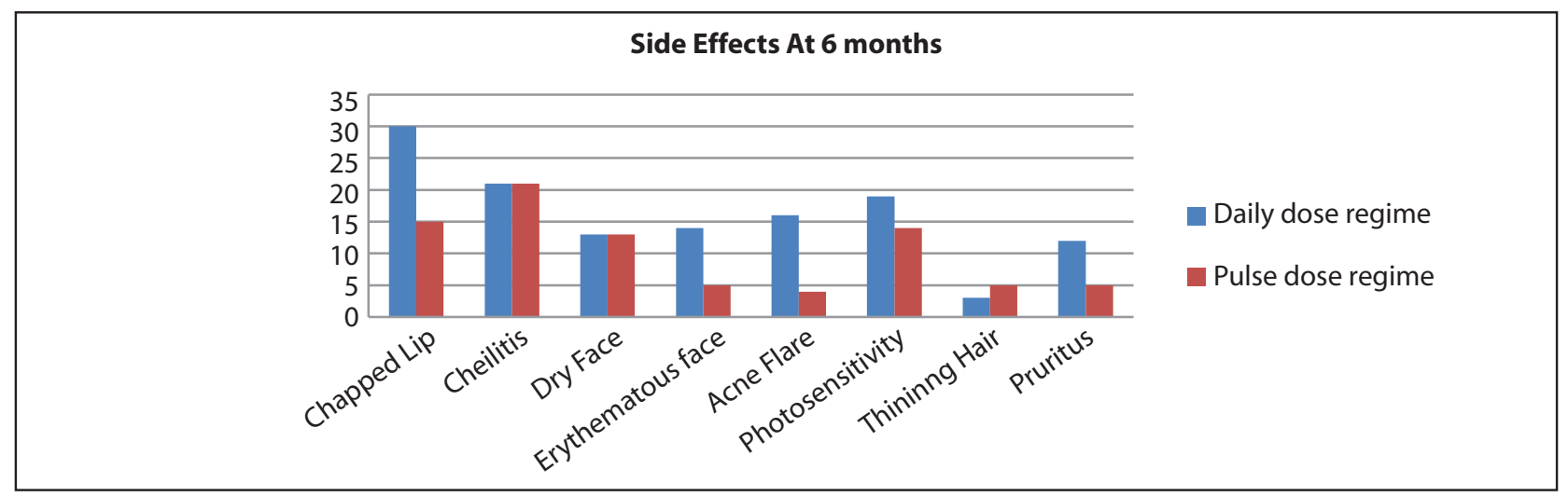

Figure 2: Cutaneous adverse effect at $6^{\text {th }}$ month

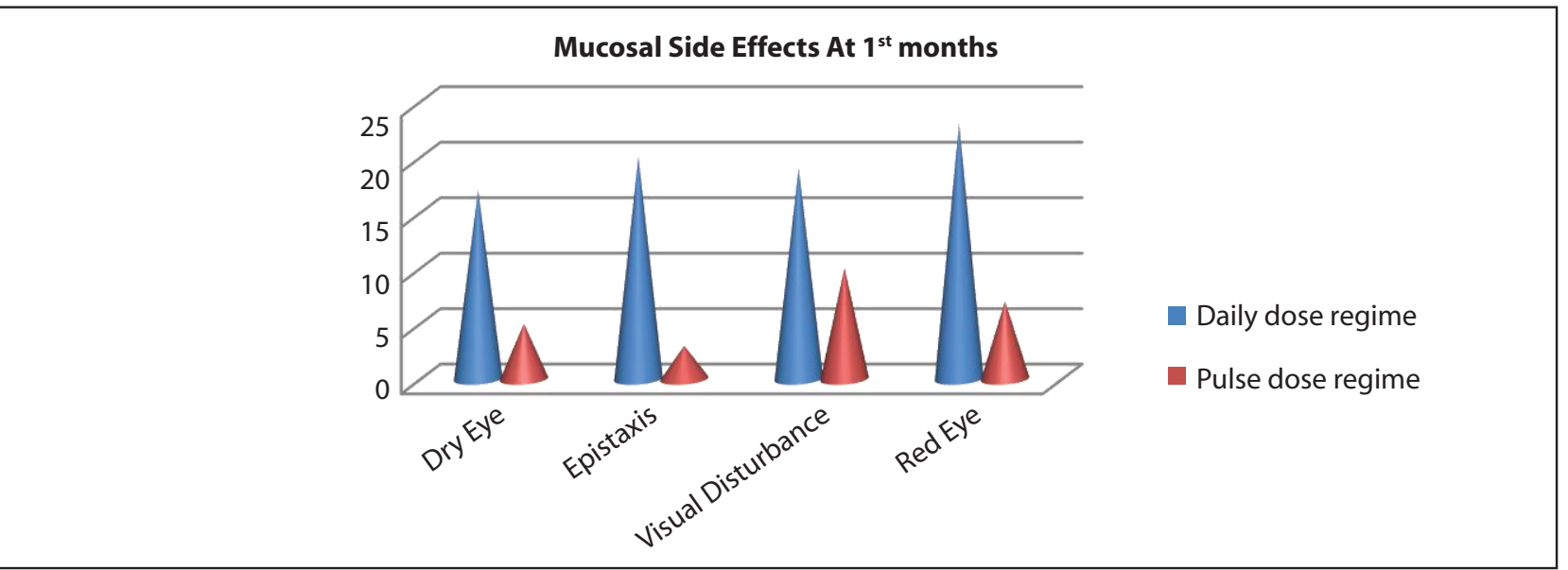

Figure 3: Mucosal adverse effects in both regimens at $1^{\text {st }}$ months

Mucosal Side Effects At 6 months

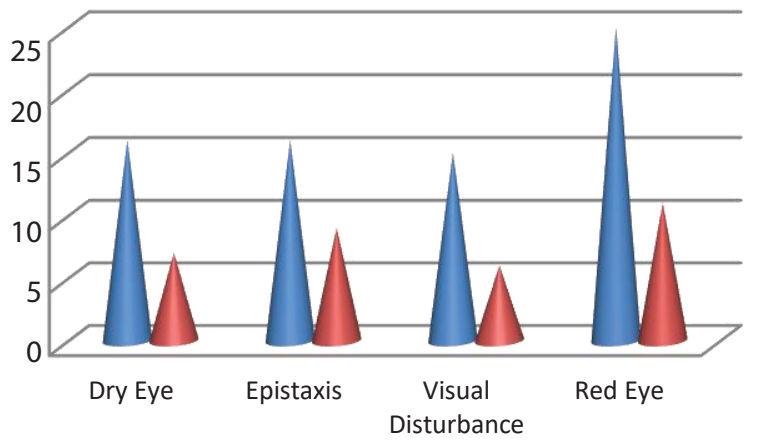

Daily dose regime

Pulse dose regime

Figure 4: Mucosal adverse effects in both regimens at 6 months

In order to improve the efficacy and tolerability of isotretinion therapy, we did a study of two different regimen with standard daily dose versus pulse dose (thrice in a week) for 6 months. Marked clinical improvement in inflammation, flattening of papular pustular lesion was observed in both the regimen but comparing both the regimen we found that patients with daily regimen showed good response throughout the therapy for six months $\left(1^{\text {st }}, 3^{\text {rd }} 6^{\text {th }}\right.$ months), where as those in pulse regimen showed moderate to poor response during early month and gradually improve by end of sixth month, with less adverse effect. In study done by Uma Shankar in India ${ }^{8}$ in different regimens, he found that patients in daily dose $(1 \mathrm{mg} / \mathrm{kg})$ show good clinically response as well as high mucocutanous side effects as compare to alternate dose, weekly dose and 
fixed daily dose of $20 \mathrm{mg}$. Similar result was found in our study where patient with daily dose had clinical improve with altered laboratory level and high dose dependent side effects.

To decrease the incident of side effects and to make the therapy protocol simpler, there are many study tried by various authors (Table 2).

In our study patients on pulse regimen have presented with less severe mucocutaneous side effects and laboratory abnormalities than in patients receiving higher doses. Hyperlipidemia is one of the more common laboratory side effects. In our study patients with pulse therapy had less hyperlipedemia compare with regular therapy. These side-effects were quite lower than other studies with a conventional dose regimen(hyperlipidemia in $20-35 \%$ and elevated liver enzymes in approximately $4-10 \%$ cases $^{10,13,14}$.

The frequency and severity of treatment-related sideeffects including cutaneous, mucosal and other were significantly higher inconventional dailyregimen as compared to pulse regimen. Previous studies had also shown that low-dose isotretinoin has lesser side-effects as compared to conventional high-dose regimens $s^{8,9,10,11,12,13}$.

The flare up of acne during first month of isotretinion is well recognized disadvantage of high dose. In our study, patients with daily regimen has higher frequency of acniform eruption comparing with pulse regimen. The lesser degree of flare up with lower dosage of isotretinoin might be related to lesser degree of activity suppression and apoptosis of sebaceous gland ${ }^{8}$. None of

\section{REFERENCES}

1. Simpson NB, Cunliffe WJ. Disorders of the Sebaceous Glands.In: Burns T Breathnach S, Cox N, Griffiths C, editors. Rook's Textbook of Dermatology, 7th ed. Oxford: Blackwell Science Ltd 2004; 43:1-34. [Full Text]

2. Thomas DR. Psychological effects of acne. J Cutan Med Surg2004; 4: 3-5. [DOI]

3. Patton TJ, Zirwas MJ, Wolverton SE. Systemic retinoids. In:Wolverton $\mathrm{SE}$, editor. Comprehensive dermatologic drugtherapy, 2nd ed. Philadelphia: Saunders; 2007: 276-95.

4. Pochi PE,Shalita AR, Strauss JS,Wedster SB, Cunliffe WJ, Katz HI.Report of the consensus Conference on Acne Classification.Washington, D.C., March 24 and patients discontinued their treatment, and the elevation was trainsient and resolved spontaneously.

Teratogenicity is well recognized and regarded as one of the most serious potential adverse effects of isotretinoin ${ }^{15}$. Fifty percent of pregnancies spontaneously abort, and of the remainder about half of the infants are born with cardiovascular or skeletal deformities ${ }^{16}$. In our patient, there were no pregnancies reported and this was achieved by repeated counselling regarding effective contraception was adopted.

Around 10.8 pt with daily dosage had depression, a causal relationship between isotretinioin and psychiatric morbidity, including depression and suicide, has not been demonstrated ${ }^{16}$. In fact, there is evidence that acne itself is associated with psychiatric morbidity. The effect of retinoids on brain dopamine systems and hypervitaminosis $A$ is associated with psychiatric symptoms including depression, and hypervitaminosis A syndrome ${ }^{16}$. It has also been suggested that many of the reported depressive adverse effects in isotretinoin therapy represent depressive or mood symptoms rather than major depression or other clinical depression syndromes $^{16}$.

Our study has some limitations. Total number of patients was very less. The study was conducted in only one center. Furthermore, the follow-up period (20 months) was relatively short.

\section{CONCLUSION}

The pulse dose regimen makes the treatment more acceptable for patients with acne vulgaris than the classical standard daily regimen, in term of side effects and cost effectiveness and patient compliance.

25, 1990.J Am Acad Dermatol. 1991;24:495-500. [Full Text]

5. Zohre Hajheydari, Mitra Mahmoudi,Korosh Vahidshahi, Arezoo Nozari.Comparison of efficacy of Azithromycin vs Clindamycin and Erythromycin in the treatment of mild to moderate acne vulgaris.Pak J Med Sci2011; 27(1):68-72. [Full Text]

6. Akman A, Durusoy C,Senturk M, Koc CK, Surkoy D, Alpossy E.Treatment of acne with intermittent and conventional isotretinoin: A randomised controlled multicenter study. Arch Dermatol Res. 2007;299:46773. [PubMed]

7. Cunliffe WJ, van de Kerkhof, Cavicchi S,Cooper A, Fyrand OL, Roaccutane treatment guidelines:results of an international survey.Dermatology. 1997;194:351-7.[PubMed] 
8. Uma Shankar Agarwal, Raj Kumar Besarwal, Kalyani Bhola.Oral isotretinoin in different dose regimens for acne vulgaris: A randomized comparative trial. IJDVL2011; 77(6):688-94.[Full Text]

9. Kaymak $Y$, Ilter $N$. The effectiveness of intermittent isotretinoin treatment in mild or moderate acne. J Eur Acad Dermatol Venereol. 2006;20:1256-60. [DOI]

10. Strauss JS, Leyden JJ, Lucky AW, Lookingbill DP, Drake LA, Hanifin JM, et al. A randomized trial of the efficacy of a new micronized formulation versus a standard formulation of isotretinoin in patients with severe recalcitrant nodular acne. J Am Acad Dermatol. 2001;45:187-95. [DOI

11. Amichai B. Long term mini doses of isotretinoin in the treatment of relapsing acne. J Dermatol. 2003;30:572. [Full Text]
12. Sardana K, Garg VK. Efficacy of low dose of isotretinoin in acne vulgaris. Indian J Dermatol Venereol Leprol. 2010;77:7-13. [DOI]

13. Amichai B, Shemer A, Grunwald MH. Low-dose isotretinoin in the treatment of acne vulgaris. $\mathrm{J} \mathrm{Am}$ Acad Dermatol. 2006;54:644-6. [DOI]

14. Palmer RA, Sidhu S, Goodwin PG. 'Microdose' isotretinoin. $\mathrm{Br} J$ Dermatol. 2000;143:205-6. [Full Text]

15. Layton A.The use of isotretinoin in acne. Dermatoendocrinol.2009;1(3):162-169. [PubMed]

16. Parker $M$, Dimity P.Isotretinoin, depression and suicide: a review of the evidence. $\mathrm{Br} J \mathrm{Gen}$ Pract.2005;55(511):134-138. [PubMed] 